\title{
La reconfiguración de la esfera pública en América Latina: un acercamiento analítico desde la ciudadanía subalterna ${ }^{i}$ The Reconfiguration of Public Sphere in Latin America: an analytic approach from subordinated citizenship
}

\section{Por: Eduardo Andrés Sandoval Forero' \& José Javier Capera Figueroa ${ }^{2}$}

1. Doctor en Sociología, Universidad Nacional Autónoma de México. Maestro en Estudios Latinoamericanos, Universidad Autónoma del Estado de México, y Antropólogo Social, Escuela Nacional de Antropología e Historia (México). Miembro de la Academia Mexicana de las Ciencias y del Sistema Nacional de Investigadores nivel III, desde 1995. Profesor invitado de universidades de Estados Unidos, América del Sur, España e Italia. Fundador y Coordinador Académico de la Maestría y el Doctorado en Educación para la Pazy la Convivencia Escolar en México. Investigador-Profesor del CIEAP, Universidad Autónoma del Estado de México. Orcid: https://orcid.org/oooo0003-1659-7588 Scholar: https://scholar.google.com.mx/citations?hl=es\&user=CNATfqoAAAAJ Contacto: forerosandoval@gmail.com

2. Politólogo de la Universidad del Tolima. Maestro en sociología política del Instituto de Investigaciones Dr. José María Luis Mora, y doctorante en Ciencias Sociales y Políticas de la Universidad Iberoamericana (México). Analista político y columnista del periódico el Nuevo Día (Colombia) y Rebelión.org (España). Colombia. Orcid: https://orcid. org/0000-0003-1823-2814 Scholar: https://scholar.google.es/citations?user=]4V1rbMAAAA]\&hl=es Contacto: caperafigueroa@gmail.com - http://josecaperafigueroa. blogspot.mx/

G OPEN ACCESS

\section{(c) $(1) \Theta(9$}

Copyright: (C) 2020 El Ágora USB.

La Revista El Ágora USB proporciona acceso abierto a todos sus contenidos bajo los términos de la licencia creative commons Atribución-NoComercial-SinDerivar 4.o Internacional (CC BY-NC-ND 4.0)

Tipo de artículo: Reflexión Recibido: noviembre de 2019 Revisado: enero de 2020

Aceptado: abril de 2020

Doi: $10.21500 / 16578031.5142$

Citar así: Sandoval Forero, E. \& Cepera Figueroa, ]. (2020). La reconfiguración de la esfera pública en América Latina: un acercamiento analítico desde la ciudadanía subalterna. El Ágora USB, 20(2). 259-271

Doi: $10.21500 / 16578031.5142$
Resumen

La democracia se ha constituido en uno de los temas de gran interés y debate para las ciencias sociales, en particular para el campo de la sociología política en América Latina. El trayecto histórico que ha tenido la esfera de lo público se ha convertido en un espacio epistémico encargado de reconfigurar las relaciones sociopolíticas que existen entre la ciudadanía y el Estado en el marco de los procesos endógenos/exógenos que constituyen la democracia en su concepción de lo público. Así pues, el propósito del presente artículo consiste en realizar un breve análisis sobre la discusión de la democracia en el marco del imaginario de los grupos subalternos que ejercen una mirada crítica sobre los procesos hegemónicos fomentados por los grupos dominantes, los cuales instituyen un modelo propio de la democracia moderna/liberal que está en función de un orden político en el plano vertical que genera actores marginados en la región.

Palabras claves: Democracia; Ciudadanía; América Latina; Lo Público; Subalternidad.

\section{Abstract}

Democracy has become one of the topics of great interest and debate for the social sciences, in particular, for the field of political sociology in Latin America. The historical journey, which has taken the public sphere has become an epistemic space responsible for reshaping the socio-political relations that exist between citizens and the state within the framework of the endogenous/exogenous processes, which constitute democracy in its conception of the public. Thus, the purpose of this article is to carry out a brief analysis of the discussion of democracy within the framework of the imaginary of junior groups that exercise a critical view of the hegemonic processes fostered by dominant groups, which institute a model typical of modern/liberal democracy, which is based on a political order at the vertical level generated by marginalized actors in the region.

Keywords: Democracy; Citizenship; Latin America; The Public; and Subordination. 


\section{Introducción}

El desarrollo de la democracia moderna está vinculado a la apropiación de tres ideas generales: la libertad, la igualdad y la fraternidad. Dichas nociones se encuentran vinculadas a un marco general de naturaleza normativa y valorativa, que sirvió como plataforma propia de los regímenes democráticos contemporáneos, ya que representó una ruta ideal para los países que optarían por operar bajo la lógica institucional de la democracia liberal/procedimental.

El proceso político de reconocer la libertad como el ideal máxime de la vida política del ciudadano en lo público, simbolizaría un punto de partida caracterizado por establecer los derechos políticos, económicos y civiles como facultades de la ciudadanía que tendrían que garantizarse en la dinámica de un Estado liberal, el cual tuviera la capacidad de avalar las responsabilidades públicas y exigir los deberes cívicos que tendría cualquier comunidad política y el ciudadano en su dimensión individual y colectiva dentro de la democracia.

Tal como lo afirma Marshall:

El elemento civil consiste en los derechos necesarios para la libertad individual-libertad de la persona, libertad de expresión, de pensamiento y de religión, el derecho a la propiedad, a cerrar contratos válidos, y el derecho a la justicia-. Este último es de una clase distinta a la de los otros porque es el derecho a defender y hacer valer todos los derechos de uno en términos de igualdad con otros y mediante los procedimientos legales (Marshall, 1949, p.302).

La perspectiva expuesta por John Dunn se caracteriza por reconocer que la democracia se constituye en un modelo político que pretende establecer un contexto igualitario sobre la ciudadanía en su dimensión económica, política, social y civil. Dicha lógica, representa una visión de las sociedades occidentales que se basan en lograr el derecho político de la libertad en función de la acumulación del capital, siendo un aspecto que demuestra como la democracia se convierte en un término asociado a los valores políticos de la modernidad (igualdad, libertad y justicia), los cuales se encuentran inmersos en el contexto del modelo liberal democrático (Dunn, 2014).

El trayecto evolutivo de la democracia según Dunn, se identifica con la figura memorable de la ciudad-estado de Atenas (polis), en donde el ágora se constituiría como el espacio por excelencia de lo público en el marco de los procesos políticos y los intereses de cierto tipo de ciudadano', que no tenía la capacidad de asumir y conocer los elementos necesarios que significa el ejercicio de la política en la vida pública, a su vez, reflejaba la forma como se desarrollaban los requerimientos y demandas que existían en la comunidad política.

Por ello, la democracia no fue asimilada desde una visión teorética sobre el modo de tener un estado pleno de convivencia (dado que fue una preocupación de los atenienses que optaron por generar acuerdos mínimos para la coexistencia y el desarrollo político de la polis), además, impulsaron el sentido sobre los valores políticos y la capacidad de politizar lo público como una manera de constituir un sujeto integral acorde a las estructuras internas de la comunidad política (Dunn, 1993).

En efecto, la narrativa liberal sobre la democracia asume una relación positiva con la dinámica de la sociedad capitalista y el modelo económico basado en la acumulación del capital, dicho vinculo se ha establecido como una visión hegemónica sobre el modo de gobernar, lo que permitió establecer un desarrollo sobre los procesos democráticos institucionales, al mismo tiempo se generaba el acenso del sistema mundo capitalista y la visión procedimental del liberalismo (Wallerstein, 1995).

La distinción del ciudadano responde al cumplimiento de ciertos requisitos en el ámbito económico, educativo, social, criterios de género y familiar en aquella época, lo que implicó una categoría excluyente que no tenía en cuenta a los barbaros, esclavos, extranjeros, hombres de colory mujeres entre otros. 
Parte de este proceso, según Dunn (2014), está asociado a los factores que generaron elementos para la democratización en las distintas sociedades del mundo, teniendo en cuenta el acenso y fortalecimiento del capitalismo global, lo que reflejó una visión general sobre el carácter de concebir esta forma de gobierno en sus distintos momentos históricos. Tal como sucedió en el momento histórico de Roma cuando asumió un modelo republicano que permitiera la agrupación de los poderes gubernamental al interior de la asamblea como un espacio para el ejercicio de la política. Aquí, tomó relevancia las características de una teoría y práctica política sustentada en ir más allá de la experiencia democrática de los griegos e intentar promover un modelo de gobierno que pudiera darle peso a la idea política de la voluntad general y el interés en lo público dentro de la asamblea.

Tanto en la República Romana como en la Antigua Grecia, ${ }^{2}$ la concepción de democracia estaba situada en establecer un sistema propio de gobierno, que pudiera instituir un logos sobre el significado de lo público y el ejercicio político de la ciudadanía al interior de esta. Por ende, el gobierno que existía en las ciudades-estado, se caracterizó por imponer convenciones sobre el ejercicio y la extensión de gobernar, dado que instauró quienes podrían participar o tener derecho al interior de la esfera política de lo público.

La perspectiva analítica de Dunn (2014), considera que la democracia actual se identifica como la forma de gobierno en donde existe una afinidad por la rentabilidad política- económica propia de las estructuras del sistema capitalista, puesto que se estableció un sistema caracterizado por el "gobierno del egoísmo", el cual promueve una visión de representatividad electoral, dando paso a la generación de un imaginario identificado por la indiferencia, al momento de participar/practicar la política en el diseño de los procesos formales o informales que constituyen lo público.

De esto modo, la finalidad del presente artículo consiste en generar una aproximación sobre la discusión de la democracia, teniendo como referencia el imaginario político de los grupos subalternos, que ejercen una mirada crítica sobre los procesos hegemónicos a cargo de los grupos dominantes que instituyen un modelo institucional propio de la democracia moderna/liberal, que responde a un orden político de carácter vertical y excluyente materializado en América Latina, lo que representa una reconfiguración de la esfera pública, resultado de una racionalidad instrumental propia de la dimensión económica - financiera que ha establecido un esquema de gobierno alineado a los intereses de la globalización neoliberal.

\section{La democracia moderna en tiempos de cambio}

La participación del sujeto en lo político, representaría una dimensión de gran importancia en la dinámica de lo público, dado que se convertiría en el eslabón orientado a reflexionar sobre la democracia en su dimensión de constituir la política como la actividad humana por excelencia en los procesos democráticos (visión clásica), dicha lógica simbolizó, el plantear un modo de organización de la política y las maneras de vincular actividades encaminadas a la politización y/o despolitización de lo público. Al mismo tiempo, la emergencia de reconocer como un valor cívico la responsabilidad del ciudadano en lo que concierne al debate, la deliberación y la reflexión sobre el ejercicio del poder político al interior del sistema democrático.

Los cambios de la sociedad moderna han influido en la concepción y praxis de la democracia, por un lado, la preponderancia que existe en dimensiones como: lo económico, lo político y la política tiene que ver con una lógica encargada de establecer un tipo de democracia que demanda un régimen político sustentada en la dinámica de la sociedad del consumo y la privatización de lo

\footnotetext{
${ }^{2}$ Las dos visiones clásicas en Grecia y Roma se caracterizaron por tener ideas sobre el modelo de pensar la democracia como forma de gobierno, es decir que en Atenas nace la noción de la democracia y en Roma se configura la república. Ambos clivajes históricospolíticos emergieron como una respuesta a la corriente de los gobiernos autocráticos, ya que fueron sistemas de gobernar que no tenían grandes diferencias en términos sustanciales.
} 
público (Bauman, 2011). A su vez, el carácter volátil permeado en lo público hace que se desplace y pierda valor la participación y responsabilidad del ciudadano frente a los poderes populares, debido a la incapacidad de asumir una postura deliberativa real. Por el contrario, el poder político y decisorio que toman los grupos corporativos, privados y financieros sobre lo público, demuestra un escenario identificado con el despojo de los bienes comunales del sujeto en su contexto sociopolítico (Márquez-Fernández, Díaz, \& Salazar, 2005).

El sentido práctico de reconocer el carácter político de la ciudadanía frente a la toma de decisiones responde a la capacidad de reconocer la racionalidad instrumental, la cual desconoce la vigencia de la esfera pública en el marco de superar la dimensión de la toma decisiones y dar paso hacia la capacidad de construir procesos horizontales propios de un horizonte utópico del sujeto en su praxis liberadora. Aunque la lógica del sistema moderno/colonial que está sustentado en un conjunto de prácticas que desconocen las contradicciones y resultados propios de la modernidad (violencia, pobreza, desigualdad, conflictos, guerras, corrupción, individualización y grupos marginados entre otros).

La figura de la democracia liberal se encuentra asociada a la dinámica del sistema capitalista, el cual se ha encargado de imponer un modelo caracterizado por las recetas/formatos al interior del Estado. Así pues, la capacidad de influencia que ejercen las organizaciones internacionales, los grupos corporativos y los sectores financieros, hacen parte de una serie de estructuras modernas que irrumpen la dimensión de una ciudadanía basada en los derechos, deberes y responsabilidades civiles como insumos para generar un desarrollo digno, humano y de calidad al interior de la sociedad civil.

Por el contrario, la capacidad de permear, mercantilizar y enajenar los espacios públicos por parte de la esfera privada y económica, responde a los intereses propios de los sectores hegemónicos que se apoderan de los poderes institucionales y establecen rutas en función de las interpelaciones del esquema neoliberal y el Estado capitalista moderno-colonial, que optan por sacar el máximo beneficio del ciudadano en materia de generar un ambiente de explotación, deshumanización e indiferencia societal.

De esta manera, las nacientes propuestas teórico- metodológicas encargadas de establecer una tipificación sobre la democracia en medio de la sociedad moderna y la globalización, se han convertido en un cúmulo de debates epistémicos que reconocen el carácter activo de la ciudadanía en los procesos democráticos y la esencia de los modelos de participación y deliberación que responde a un tipo de régimen político al interior de una extensión sustantiva, procedimental, constitucional o procesal de la democracia.

El proceso de asumir un rol político sobre los conflictos inherentes a la constitución de la democracia, se configuran como un área que pone en juego las maneras de ejercer el poder político de los grupos hegemónicos y la demanda de los actores subalternos. Así pues, la relación de la democracia y el capitalismo moderno se convirtió en una estructura político- institucional, que promueve un esquema sobre lo que representa lo público y sus cambios al interior de la sociedad neoliberal.

Por ello, la lógica expuesta por Charles Tilly sobre los cuatro tipos de definiciones que existen de la democracia moderna (procesal, constitucional, procedimental y sustantiva), se caracterizan por asumir una dimensión integral que pretende identificar los procedimientos que requiere tenery realizar un país para autoproclamarse o señalarle como democrático. Igualmente, la narrativa expuesta por Tilly, parte de retomar los criterios mostrados por Robert Dahl, el cual reconoce que es necesario la existencia de la participación efectiva, las elecciones abiertas y competitivas, la igualdad del voto, el control de la agenda política y la compresión del proceso democrático por parte de la ciudadanía (Tilly, 2010).

El proceso de reconocer, los elementos que constituyen la democracia para Tilly, se encuentra vinculado a la capacidad de concebir una conexión entre el ejercicio político de la ciudadanía, la 
capacidad de movilización de la política y el tipo la receptividad del Estado frente a las demandas del sujeto en el ámbito individual y colectivo. Por esta razón, el sentido democrático de un régimen está basado en el desarrollo de los procesos políticos del gobierno y su capacidad de garantizar las circunstancias necesarias para la acción política, la vinculación de los derechos y las responsabilidades del ciudadano como un sujeto político en lo público.

Por un lado, el Estado tiene la obligación de sancionar aquellos individuos que no cumplen con el marco normativo, procedimental y vinculante que existen en la carta magna y hace parte del principio del ordenamiento jurídico, que tiene como función la conservación y ampliación de una democracia auténtica fundamentada en prácticas propias del ciudadano en su praxis sobre la participación, la representación y el ejercicio del poder político al interior de la comunidad. En efecto, parte de esta discusión responde a reconocer que la democracia sustantiva se caracteriza por tener

Un enfoque que se fija en las condiciones de vida y política que promueve un determinado régimen, es decir, tiene en cuenta el bienestar humano, la libertad individual, la seguridad, la equidad, la igualdad social, la deliberación pública y la resolución pacífica de los conflictos (Tilly, 2010, p.38).

La dimensión de un régimen democrático en la perspectiva de Tilly, tiene que ver con la interacción entre el Estado, la ciudadanía y las instituciones, siendo una correspondencia que contribuye a la constitución de tres procesos políticos de gran importancia: primero, las redes de confianza interpersonales, segundo las desigualdades categóricas; y tercero, la presencia de centros autónomos del poder que se enmarca con la dinámica de impulsar procesos de democratización o conllevar a un escenario de desdemocratización.

De esta manera, la democracia moderna/liberal vinculada al marco de la configuración de lo público, responde a un tipo de sociedad acorde a los requerimientos de la globalización y la modulación del sistema capitalista. La crítica a la visión liberal está vinculada a las demandas de los actores marginados, que NO hacen parte de los procesos institucionales y el Estado neoliberal, el cual promueve un espacio político asimétrico entre los poderes populares de la ciudadanía y la influencia del poder político por parte de la esfera privada en la toma de disposiciones institucionales, lo que significa, analizar la dinámica de los grupos hegemónicos instaurados en la lógica privatizadora de lo público.

Uno de los problemas centrales generado en la democracia moderna/liberal, es la falta de capacidades para crear soluciones a problemáticas estructurales en materia social, política, económica y cultural que exige la ciudadanía. Esto es resultado de los cambios que trae consigo la globalización neoliberal, la cual contribuye a las distintas crisis en los diferentes campos de la coexistencia de la política, tal como es la crisis de los partidos, los procesos migratorios, la explotación y ampliación de la marginalización, a su vez, el control político desde arriba sobre los esquemas de producción por parte de las élites y el capital privado dentro de la democracia institucionalizada propia del Estado liberal.

Al mismo tiempo, aparece la precariedad por garantizar los derechos sociales, económicos, políticos y civiles que requiere la ciudadanía, ya que es un factor que refleja la incapacidad por implantar parámetros en el marco de la resolución de los conflictos y la normalización de las demandas que configuran los procesos políticos del ciudadano al interior del Estado moderno.

\section{Los daños colaterales de la democracia moderna/liberal}

La dinamización del sistema mundo- moderno en lo que concierne el desarrollo del capitalismo, se constituyó como un momento histórico que desplazó la dimensión de la política por la lógica de la esfera económica, lo que genero un ambiente caracterizado por la despolitización de lo público y la constitución del proceso político que hace parte de una ciudadanía participativa y una democracia 
sustantiva, la cual se enfoca en asumir una dimensión procedimental sobre el tratamiento de los conflictos y una práctica asistencialista en torno a las demandas reales de los grupos sociales, siendo un factor que influye en la corriente de democratización que arguye la sociedad civil, bajo la estipulación de reglas conforme a los intereses constitutivos del Estado social/liberal (Wallerstein, 1995).

En este contexto, emerge la necesidad de concebir un modelo ideal de la democracia, el cual partiera de asumir las necesidades reales de los grupos sociales marginados en sus territorios. Dicha visión tiene que ver con una crítica desde la praxis de los actores subalternos, que optan por superar los vacíos del Estado social/liberal y la democracia procedimental, ya que no responde a las demandas populares que buscan generar procesos de transformación social en su diario vivir al interior de la comunidad política.

Por el contrario, la preponderancia hacia la esfera privada y la economía de mercado, ha reflejado una afinidad por hacer de la democracia un régimen político funcional al orden hegemónico que se sustenta en la tesis de explotar/dominar los grupos periféricos y generar condiciones de precariedad al interior de los espacios políticos que hacen parte del sistema de deliberación comunitaria de la sociedad moderna.

El sentido de la sociedad moderna se instituye por implementar un tipo de racionalidad instrumental, la cual se articula con las prácticas de los grupos hegemónicos, los cuales controlan las fuerzas de trabajo del mercado, asimismo, impulsan un modelo que pretende ser eficiente, productivo y eficaz en los procesos que conforman las estructuras político- burocráticas propias de una democracia procedimental. Así pues, se instaura en el Estado liberal una corriente orientada a la re-producción y ampliación del capital, así como a la mercantilización de los derechos socio-políticos de la ciudadanía en un contexto de concebir al Estado como una empresa capitalista y la sociedad civil como un proyecto neoliberal.

La emergencia de la globalización neoliberal, encargada de imponer un modelo económico sustentado en la desigualdad estructural y la explotación del hombre sobre la naturaleza, refleja una perspectiva en donde la democracia de corte liberal carece de las condiciones y estrategias para solventar las demandas internas/externas que hacen parte del proyecto por democratizar el régimen político de una sociedad (Tilly, 2010). En efecto, se implementa una estructura política funcional a la lógica sistémica de una modernidad/colonialidad, la cual sirve como base para los intereses de los grupos hegemónicos sobre los territorios.

La dimensión de la democracia colateral tiene que ver con la pérdida real del Estado social y la precariedad que se refleja en la ciudadanía, dado que

Un Estado es "social" cuando promueve el principio del seguro colectivo, respaldado por la comunidad, contra el infortunio individual y sus consecuencias. Este principio - una vez declarado, puesto en marcha e instalado en la confianza pública -es el que eleva la "sociedad imaginada" al nivel de una "totalidad genuina"- una comunidad tangible, perceptible y vivida y, en consecuencia, reemplaza (en palabras de John Dunn), el "orden del egoísmo", que engendra desconfianza y suspicacia, por el "orden de la igualdad" que inspira confianza y solidaridad (Bauman, 2011, p.27).

Por tal motivo, la incapacidad de la democracia liberal por dar alternativas a las demandas de los grupos excluidos o llamados parias de la misma, representa una visión profunda sobre los límites que existen en los procesos democráticos propios de la modernidad/colonial, la cual se ha encargado de profundizar los problemas estructurales como la migración, la xenofobia, la crisis de representatividad de los partidos, la desconfianza hacia la democracia y las inseguridades en el plano de la coexistencia del sujeto dentro de la sociedad civil.

El problema de una sociedad basada en el consumo y la normalización de las formas de violencias y explotación repercute en la lógica de una modernidad apoderada por el uno por ciento de 
los sectores millonarios del mundo, los cuales establecen un orden transnacional que desconoce las necesidades reales de los actores subalternos. Tal como sucede en América Latina donde la dinámica de la acumulación por desposesión se logra evidenciar en los procesos de gentrificación de las ciudades, la migración constate de lo rural a lo urbano y la precariedad de un régimen político que no logra garantizar los derechos humanos, económicos, políticos y sociales de la ciudadanía para así establecer espacios de politización sobre lo público, partiendo de las necesidades y demandas reales que existe en su comunidad política.

Ello simboliza reconocer que la esencia de los daños colaterales de la democracia moderna/liberal, se encuentra basada en la dinámica de la globalización neoliberal, la cual ha impuesto un tipo de racionalidad en función de las exigencias el sector privado transnacional y las instituciones financieras que han hecho de lo público una versión de la mercantilización de las instituciones políticas democráticas al servicio de los interés de los grupos corporativos, que han contribuido al despojo de los valores e ideales de la democracia en su dimensión ontológica y epistémica, que asume la dimensión ética de un ciudadano integro que tenga la capacidad reflexiva en el momento de tomar decisiones en medio de un escenario de deliberación política al interior de su comunidad sociopolítica.

\section{Democracia y ciudadanía subalterna en la reconfiguración de lo público}

La lógica de una ciudadanía critica en función de una democracia subalterna en América Latina, responde a lo que menciona el filósofo francés Jacques Rancière sobre el odio a la democracia y la incapacidad que tiene este sistema de gobierno, al no garantizar las nociones reales que demandan los grupos sociales en cualquier gobierno democrático.

Jacques parte de señala que la democracia en su génesis tiene un significado revolucionario que irrumpe con la lógica de la globalización neoliberal, la cual tiene que ver con lo público y su relación con los poderes populares, lo que implica una tarea de constante trabajo. La segunda, responde a la cortina de humo que existe con respecto a las sociedades que se autodenominan democráticas, pero en su interior existe un gobierno caracterizado por oligarquías que se apoderan de los espacios de representación institucional; y la tercera, está vinculada al sentimiento/pensamiento de odio a la democracia que existe en la actualidad, ya que es un sentir nuevo el cual tiene afinidad con los grupos sociales, a su vez, señala la dimensión profunda de los daños colaterales en lo público (Ranciere, 2012).

La perspectiva de reconocer que la política y la democracia hacen parte del mismo proceso, y por ende no puede existir una diferenciación sustancial ya que contribuiría al establecimiento de una lógica policial a cargo del Estado, debido a que está pensando en distribuir los espacios socio-políticos para los grupos hegemónicos. Así pues, la democracia tendría que optar por generar un espacio común que permitiera la apropiación de lo público, a través de la praxis liberadora de los grupos subalternos que demandan ir más allá del velo colonialista de las élites al interior de las instituciones modernas.

Tal como lo argumenta Boaventura de Sousa, cuando describe que:

En las sociedades capitalistas, principalmente, existen dos formas: el Estado de bienestar en el centro del sistema mundial y el Estado desarrollista en la periferia y semiperiferia del sistema mundial. A medida que fue estatalizando la regulación, el Estado la convirtió en campo para la lucha política, razón por la cual acabó politizándose. Del mismo modo que la ciudadanía se configuró desde el trabajo, la democracia estuvo desde el principio ligada a la socialización de la economía (De Sousa Santos, 2004, p.7).

Así pues, la dinámica por superar la despolitización de lo público y la perdida de los espacios de deliberación sobre las necesidades estructurales y las alternativas por superar una lógica de exclusión, pobreza, desigualdad y precariedad que se generó en la democracia liberal y la sociedad moderna, tiene que ver con la emergencia de un horizonte en donde el Estado no pueda seguir la 
re-producción de una lógica de privatización de lo público, a cargo del sector privado/mercado, para dar el salto hacia una democracia fundada en las luchas populares de los grupos subalternos en sus territorios, lo que implica reconocer los límites del modelo liberal que no logra asimilar las reivindicación socio-cultural de los grupos oprimidos (pueblos indígenas, negros, campesinos, colectivos feministas, movimientos sociales y pueblos populares).

La crisis estructural y sistémica que evidencia América Latina al presentar una serie de democracias de baja o mediana intensidad según las mediciones/estándares internacionales de naturaleza instrumentalistas, refleja un desconocimiento sobre las necesidades reales que existen en los territorios desde y con los de abajo, siendo el reflejo de un tipo de razón orientada a una praxis liberadora en función de superar la tendencia de la privatización de lo público.

Por tal motivo, la democracia en la región se enfrenta a la superación de un neoliberalismo que transformó el orden político de las instituciones públicas, lo que conllevó a un escenario donde el sector privado impuso una agenda política sobre la toma de decisiones y la configuración de la política al interior de la democracia en los distintos países. Una muestra de este escenario se debe a la aplicación en la década de los ochenta y noventa de los planes de ajustes estructurales en el marco de una era de la neoliberalización de la sociedad civil y la privatización del Estado acorde a las exigencias del sistema capitalista (De Sousa Santos, 2004).

La noción de Rancière acerca de superar la lógica de la democracia, no tiene que ver con una forma de gobierno perse, responde a una narrativa que intenta reconocer la superación la lógica liberal de darle el poder a los grupos hegemónicos y legitimar toda acción como un reflejo de la democracia (Ranciere, 2012). Por el contrario, significa ir más allá de los modelos de un sistema de representación basado en los intereses de las oligarquías, tarea que se propone con esquemas subalternos que tengan la capacidad de hacer grietas a la dimensión económica del poder político hegemónico y dar paso a las reivindicaciones socioculturales de los actores periféricos.

El sentido práctico de asumir una crítica a la modernización del proceso político institucional, el cual desconoce las demandas/necesidades de los grupos marginados, dado que dicho modelo de democracia no está sustentando en una perspectiva sustantiva, dialógica y abierta por asumir una pluralidad de narrativas y prácticas colaborativas que sean la base para ofrecer espacios de participación, deliberación y toma de decisiones en la agenda política que necesita el tercer estado dentro de la sociedad civil.

La capacidad de canalizar las inconformidades de los grupos subalternos y re-politizar lo público en una dimensión socio-política, se convierte en un reto que demanda hacer peso a la corriente eminentemente económica sobre la toma de decisiones de lo político para así promover un ambiente político que le exija a la democracia dar el salto hacia la democratización, pluralidad y praxis que integran las demandas de los actores subalternos en medio de un modelo que pueda superar el velo de la democracia moderna/liberal y los vacíos profundos que se manifiestan como daños colaterales de la misma.

De este modo, la reconfiguración de lo público a partir de la praxis de una ciudadanía situada en la subalternidad en América Latina, tiene que ver con aquellas expresiones no - institucionales, normativas o lineales de la democracia, para dar paso a una alteridad congruente con las formas subalternas y populares de hacer democracia desde abajo, teniendo en cuenta, las experiencias pacificadoras, autónomas y territoriales que han ejercido en sus comunidades pueblos, movimientos y sectores sociales caracterizados como subalternos (campesinos, populares y étnicos). Por ende, las luchas socio-culturales enfocadas a establecer una praxis en defensa de la vida, el territorio, la naturaleza y los tejidos comunitarios, son el reflejo de los procesos autonómicos de resistencia popular y descolonial en la región. En esta lógica, se enmarca la disputa de estos movimientos sociales y contestatarios por establecer una ruta contrahegemónica que pueda exponer modelos alternativos a la visión de una democracia cooptada por los poderes moderno/coloniales propias del sistema mundo-capitalista. 
Múltiples son las experiencias antisistémicas de los pueblos en movimiento que cuestionan y fragmentan la democracia formal representativa neoliberal, oponiendo, en unos casos construcciones colectivas democráticas de participación directa, y en otros, en manifestaciones y marchas que luchan por la tierra y la autonomía desafiando el poder y de la democracia hegemónica. A manera de ejemplo podemos citar al Movimiento Zapatista en México, los movimientos de los sin tierra en Brasil, las luchas de los Mapuches en Chile y Argentina, las luchas por la autonomía de los indígenas y campesinos de Colombia, Ecuador, Bolivia, Perú y Paraguay. Luchas que se suman los movimientos feministas antisistémicos que combaten las estructuras patriarcales de la sociedad y que también aquilatan las resistencias promovidas por el Foro Social Mundial.

Tales experiencias son el reflejo de propuestas sub-alternas que se identifica con el giro descolonizador orientado a politizar lo público a partir de la praxis liberadora de los grupos oprimidos, lo que implica superar la lógica de un modelo democrático liberal de naturaleza minimalista que se encarga de establecer estructuras cerradas, arcaicas y restrictivas que no permiten los procesos de movilización/movilidad humana en función del interés público de la comunidad política.

Las propuestas y la práctica subalternas constituyen la muestra de acciones que están localizadas en el debate por cuestionar la concentración del poder, la excepcionalidad de la democracia liberal en su versión minimalista y los espacios cerrados a cargo de los grupos dominantes que desconocen las demandas y sentí-pensares de los actores populares que en su praxis liberadora expresan modos alternos de ir más allá de la democracia procedimental, aunque, dichas expresiones son el reflejo del imaginario subalternos del sujeto que asume la praxis desde abajo que permite reconocer los límites y marginalidad que existe en el modelo democrático liberal de nuestra época.

\section{La emergencia de la educación subalterna}

La necesidad de proponer nuevos esquemas que tengan el principio de cuestionar los órdenes normativos que se instituyen en las instituciones de educación en todos sus niveles (básica, media, técnica y superior), simboliza una apuesta por generar un sujeto crítico en su pensamiento y reflexivo en su praxis encaminada a constituir procesos emergentes en el marco de un ambiente subalternos frente al colonialismo interno de la sociedad moderna - capitalista.

El sentido práctico de generar alternativas desde adentro que sean conducentes a la superación del imaginario colectivo etnocéntrico y eurocentrado del saber, tiene que ver con una disputa epistémico - política frente a la dinámica de grupos sociales hegemónicos, los cuales imponen una racionalidad instrumental sustentada en el interés individual y el capital privado funcional a los requerimientos de una sociedad globalizada y un Estado neoliberal. Así pues, la emergencia de una ciudadanía que cuestione los escenarios educativos en el marco del pensamiento crítico y las necesidades de los de abajo, responde a una dinámica por descolonizar las estructuras tradicionales y dar el paso a una praxis liberadora en comunidad.

Las experiencias subalternas en el plano educativo son el reflejo de la construcción de modelos alternos, los cuales pretenden refutar los esquemas modernos/coloniales basados en principios como: el etnocentrismo, la violencia, el racismo, la xenofobia y la discriminaciones sociales, económicas, políticas y culturales entre otras, que afectan de forma radical los tejidos comunitarios propios del reconocimiento de la identidad y la praxis subalterna del sujeto en escenarios colectivos.

Tal como lo argumenta, el filósofo venezolano Álvaro Márquez - Fernández en materia de la subalternización de las acciones constitutivas de otras realidades, y la emergencia de formas educativas sustentadas en el pensar, el sentir y hacer con los de abajo:

Las prácticas de pensamiento versan sobre las experiencias racionales por medio de las cuales los sujetos de una cultura logran la producción de valores en un intercambio de intereses y necesidades con la finalidad de consolidar en el tiempo estructuras de convivencias lo más justas y equitativas posibles. Es 
lógico que estas prácticas filosóficas estén en sincronía con formas de representación del poder, a través de la política que sirve de trama o tejido para la interacción social" (Márquez-Fernández, 2012, p.2).

En este sentido, se propone la superación de vicisitudes propias de globalización neoliberal que promueve un pensamiento segregado, excluyente y violento, el cual pretende imponer una racionalidad propia de los actores hegemónicos que establecen una sociedad fragmentada, la des-politización de lo público y la invisibilización del sujeto oprimido. Por ello, la educación subalterna simboliza una iniciativa por configurar prácticas en el marco de un pensamiento horizontal que logre coexistir con la otredad desde su propia experiencia, pero también logre la convergencia de ideas orientadas a las transformaciones de la realidad sociocultural de los grupos explotados.

La descolonización refleja una iniciativa contrahegemónica que pretende generar procesos de coexistencia desde la diferencia, a su vez, responde a las causas por construir alternativas desde abajo, lo cual permita poner en cuestionamiento la modulación del Estado capitalista y la sociedad neoliberal, que ha constituido un sujeto en función de los intereses privados y la individualización de lo público, debido a que conlleva a un escenario contradictorio del proyecto liberador de los de abajo (Sandoval, 2016).

De este modo, la subalternización educativa pensada desde la praxis del sujeto, tiene que ver con una crítica radical a las formas de concebir los procesos de exclusión y negación de la otredad, para dar el salto hacia modos de integración horizontal y colaborativos que puedan cuestionar las estructuras cerradas a cargo de los grupos dominantes que instituyen un poder político, el cual desconoce la alteridad del sujeto en lo colectivo. Al mismo tiempo, se opta por la reconfiguración de la formación ciudadana en el ámbito educativo, para así conseguir el reconocimiento intersubjetivo de las transformaciones sociales que requieren la sociedad contemporánea (Alonso, ] \& Ramírez, ], 1997).

La crítica a la sociedad moderna propia del sistema mundo - capitalista, representa un escenario que desconoce la diferenciación de la subjetividad, las emociones y la divergencia de pensamientos encargados de refutar los modelos modernos/colonial propios de la sociedad neoliberal. La apuesta por una educación subalterna se articula a la pretensión de un universalismo epistémico y un modelo de dominación basado en los principios del capitalismo global. Teniendo presente la dinámica de

Los movimientos de educación y comunicación popular inspirados por Fals -con su investigación acción participativa (IAP) - y Freire, ya que motivaron una infinidad de movilizaciones transformadoras en los 70 y 80 , con frecuencia de la mano de las luchas revolucionarias alimentadas por el marxismo y la diversidad de izquierdas, pero siempre enfatizando la necesidad de tomar en serio los conocimientos de los pueblos. Hoy en día, en las vertientes autonómicas y del pensamiento de la Tierra, encontramos ecos de este valioso legado, aunque con una radicalización epistémica mayor que la de las propuestas de aquellas décadas (Walsh, 2017:60).

Al mismo tiempo, la apuesta por una educación subalternizada y descolonizada, busca superar las secuelas de la globalización neoliberal en la sociedad, ya que ha generado un imaginario negativo frente a la otredad, dado que se pretenden establecer rutas alternas que provengan de la praxis populary el proyecto desde abajo, es decir, formas constitutivas que aporten elementos epistémicos, teóricos y prácticos a partir de la experiencia de transformación de los espacios societales.

La emergencia de paradigmas subalternos en el campo de la educación también representa una apuesta por elaborar modelos plurales que proponga alternativas desde adentro a problemas estructurales como la violencia, la pobreza, la desigualdad, la negación y la exclusión sociocultural, tal como se evidencia en la sociedad moderna/capitalista. Por ende, es de gran importancia 
establecer otras formas de hacer política desde el sujeto, contrario a las lógicas modernas de pensar los cambios desde el Estado, ya que el sentido práctico radica en las luchas de abajo en función de superar las contradicciones del capital en la sociedad contemporánea (Walsh, 2017).

El proceso de la descolonización no solamente radica en una crítica ad doc, sino en la reconceptualización de la realidad, a partir de la experiencia y resistencia desde abajo del sujeto. La necesidad de sumar luchas que tengan una legitimidad de los grupos sociales refleja la necesidad de construir conocimientos de forma horizontal y bajo una lógica colaborativa que sea una apuesta por descolonizar las formas de ejercer conocimiento sin caer en los plano normativos e institucionales propio de la modernidad/colonialidad.

La propuesta de una educación subalterna se identifica con la lógica de un proyecto subalterno que, apuesta por superar la estructura de los grupos dominantes, es decir, el sentido de ir a contrapelo de la corriente clásica de enseñar por enseñar y reconocer que cualquier ejercicio pedagógico debe tener en su interior una praxis por asumir las responsabilidades del sujeto y su papel histórico de transformación de la realidad social.

Las luchas populares que motivan los procesos de movilización como un antecedente que demuestra la inconformidad de los proyectos políticos en los Estados por parte de la ciudadanía, simboliza una práctica que pretende superar las estructuras modernas para dar paso a una praxis descolonizadora que establezca diálogos desde una interculturalidad crítica que tenga en cuenta las demandas de los de abajo, a su vez, un dinámica por reconstituir los procesos de liberación que sean resultado de la experiencia subalterna del cambio social en nuestros tiempos.

En definitiva, la descolonización del proceso pedagógico no solo tiene que ver con buscar e implementar estrategias de enseñanza, sino con generar un pensamiento crítico que tenga la capacidad de instituir reflexiones de largo alcance sobre los contextos en que se desarrolla la historia de vida del sujeto y su vínculo con los movimientos populares encargados de apostar por un ambiente de transformación social en el marco del pensamiento subalterno Latinoamericano.

\section{A modo de conclusión}

Los daños colaterales que ha tenido la democracia liberal en la sociedad moderna, la cual está caracterizada por las crisis sistémicas (existencias, emocionales, ecológicas, políticas, económicas e identitarias), hace parte de los vacíos generados por la privatización de lo público/institucional y la dinámica de una globalización de naturaleza neoliberal/extractivista, que apuesta por el crecimiento del capital y la deshumanización del sujeto en comunidad. Por ello, la pérdida de la concepción de lo público, tal como fue asumida por los griegos en su visión clásica demuestra la transformación histórica que ha tenido el debate epistémico sobre la democracia en las ciencias sociales.

La incapacidad de lograr una democracia sustantiva (holística) que pueda garantizar de forma integrar los derechos, deberes y responsabilidades público/privado de la ciudadanía en el marco de un Estado social de derecho, significa un reflejo de la preeminencia que preexiste del pensamiento liberal que opta por una democracia de corte procedimental/procesal la cual no tiene en cuenta las necesidades, demandas y manifestaciones populares y desde debajo de los grupos subalternos. La disputa por la justicia social y la democratización de los procesos políticos de lo público se constituye en una lucha subalternas de los grupos de abajo, que exigen otras formas de ejercery hacer la democracia que estén más allá del velo del colonialismo liberal. Asimismo, se configura como un modelo que cuestiona los modos tradicionales de pensar la democracia a partir de los intereses/necesidades de los grupos hegemónicos.

Por tal motivo, la posibilidad de reconocer que los daños colaterales de la democracia tienen que ver con los vacíos distributivos de un modelo institucional que no tiene congruencia y coherencia con las disposiciones societales/sistémicas y las reivindicaciones socio-culturales de los grupos 
marginados, ya que está mentalizado en reproducir un tipo de desarrollo propio de la globalización y el sistema capitalista (Bauman, 2011). La lucha por ir más allá de la corriente eurocéntrica de la democracia tiene que ver con reconocer el odio hacia la elitización del poder político, a cargo de grupúsculos que han impuesto una racionalidad económica e instrumental funcional a la privatización de la esfera pública.

El proyecto de reconfigurar la esfera pública desde la perspectiva de una ciudadanía subalterna, tiene que ver con las grietas que se puedan realizar al capital privado y la dinámica de una democracia procedimental, para dar el salto hacia una dimensión sustantiva, integral y holística desde y con los de abajo, para así asumir un giro descolonizador que permita re-pensar la democracia y re-fundar el Estado, a partir de la demanda y exigencias de los grupos subalternos en sus territorios.

En últimas, la esfera pública en América Latina se encuentra en medio de la re-producción de un orden geopolítico colonialista a cargo de los grupos hegemónicos que han establecido una democracia procedimental propia del sistema capitalista. Paralelamente, las disputas desde abajo y en la perspectiva descolonizadoras que han realizado los movimientos sociales, feministas, estudiantiles, obreros, sindicalistas, pacifistas, juveniles, indígenas y populares entre otros, los cuales han suscitado formas "otras" de re-pensar y ejercer la democracia que pueda ir más allá de la concepción moderna/procedimental, resultado de una preponderancia electoral en los sistemas en donde impera la democracia como forma de gobierno.

Las luchas subalternas de estos actores marginalizados de la sociedad y la economía son la muestra de la emergencia por establecer modelos alternativos de democracia que tengan la capacidad de cuestionar y asumir un rol deliberativo a través de una praxis subalterna, enfocada a establecer una dinámica horizontal, crítica y reflexiva sobre las representaciones de la democracia y la re-significación de lo público en los territorios, las comunidades y los grupos excluidos que optan por un desplazamiento descolonizador que sea el reflejo de experiencias desde y con los de abajo, encaminadas a cuestionar el sistema mundial-capitalista y la globalización neoliberal de nuestros tiempos.

Esta reconfiguración de la democracia desde abajo se constituye en sentido amplio, "en otro mundo posible" en lucha política y social contra la degradación de la libertad, la justicia y la igualdad de la democracia formal neoliberal, sustentada en la pobreza, la miseria, la desigualdad, la inequidad, la corrupción, la exclusión y las violencias de un modelo representativo que por su fracaso denigra a la democracia.

\section{Referencias bibliográficas}

Alonso, ] \& Ramírez, J. (1997). La democracia de los de abajo en México. México: La Jornada ediciones.

Bauman, Z. (2011). Daños colaterales. Desigualdades sociales en la era global. México: Fondo de Cultura Económica.

De Sousa Santos, B. (2004). Reinventar la democracia: reinventar el Estado. Ecuador: Editorial Abya Yala.

Dunn, J. (12 de marzo de 1993). Democracia: la política de construir, defender y ejemplificar una comunidad: Europa hoy. http://e-spacio.uned.es/fez/eserv/bibliuned:filopoli-1993-1-5021E2B5-721B-C9 46-18D8-7239548EC3FB/democracia.pdf

Dunn, J. (2014). Libertad para el pueblo. México: Fondo de Cultura Económica.

Márquez-Fernández, Á. (2012). The role of political construction of intercultural praxis. Revista FAIA, 1-14.

Márquez-Fernández, Á., Díaz, Z., \& Salazar, R. (2005). Transformaciones sociopolíticas recientes en América Latina. México: Libros en red - Insumisos Latinoamericanos.

Marshall, T. (1949). Ciudadanía y clase social. Reis (79), 197-344. http://catedras. fsoc.uba.ar/isuani/marshall.pdf

Ranciere, J. (2012). El odio a la democracia. Buenos Aires: Amorrortu.

Sandoval-Forero, E. (2016). Educación para la paz integral - Memoria, interculturalidad y decolonialidad. Bogotá: ARFO Editores e Impresores LTDA. 
Tilly, C. (2010). Democracia. Madrid: Akal.

Walsh, C. (2017). Pedagogías decoloniales: Prácticas insurgentes de resistir, (re)existiry (re)vivir. Ecuador: Ediciones Abya-Yala.

Wallerstein, I. (2 de octubre de 1995). La reestructuración capitalista y el sistema mundo. Conferencia magistral en el XX Congreso de la Asociación Latinoamericana de Sociología. México. https://www. flacsoandes.edu.ec/web/imagesFTP/1265665449.La_reestructuracion_capitalista_y_el_sistema.pdf 